\title{
GÊNERO E RAÇA NOS DISCURSOS DE CAROLINA DE JESUS E CLARICE LISPECTOR
}

\section{GENDER AND RACE IN THE DISCOURSES OF CAROLINA DE JESUS AND CLARICE LISPECTOR}

\section{Letícia Pereira de Andrade}

Resumo: Ao analisar narrativas de autoras socioculturalmente diferentes - Meu estranho diário, de Carolina Maria de Jesus (1914-1977) e Aprendendo a viver, de Clarice Lispector (1920-1977) - é possível perceber a configuração de gênero e raça impressos a partir dos textos. A "re-presentação" é mediada por recortes afetivos que recuam, estabelecem filiações e vínculos com outros territórios enunciativos, refletindo o posicionamento do indivíduo como sujeito social. Desse modo, os diários de Carolina e as crônicas confessionais de Clarice contrapõem valores, estabelecendo critérios e novas perspectivas sobre si e sobre seu contexto.

Palavras-chaves: Representação. Mulheres. Gênero e raça.

Abstract: By analyzing narratives of socio-culturally different authors - My strange diary of Carolina Maria de Jesus (1914-1977) and Learning to Live of Clarice Lispector (1920-1977) - you can see the configuration of gender and race printed from texts. The "re-presentation" is mediated by affective cutouts that recede, affiliations and establish links with other territories enunciation, reflecting the position of the individual as a social subject. Thus, the diaries of Carolina and confessional chronic of Clarice opposed values, establishing criteria and new perspectives about themselves and their context.

Keywords: Representation. Women. Gender and race.

\footnotetext{
* Formada em Letras pela UFMS. Especialização em Latim e estudos diacrônicos pela UEMS. Mestrado em Letras pela UFMS. Atualmente atua na UEMS. Doutoranda pela UFRGS. Email: leticiauems@gmail.com.

1 Segundo Magnabosco (2002), "presentação" traz a emergência da subjetividade do sujeito que vivencia, que está dentro do processo e, por esse motivo, descentraliza territórios de gêneros ao transitar pelos caminhos fluídos da memória e linguagem afetivas.
} 
1. BARAlHANDO DOIS TEXTOS

"O que eu gostaria de ser era uma lutadora. Quero dizer, uma pessoa que luta pelo bem dos outros. Isso desde pequena eu quis. Por que foi o destino me levando a escrever o que já escrevi [...]?”

(Clarice Lispector)

"Quando eu era menina o meu sonho era ser homem para defender o Brasil porque eu lia a história do Brasil e ficava sabendo que existia guerra. Só li os nomes masculinos como defensor da pátria. [...] Não tenho força física, mas as minhas palavras ferem mais do que espada. $E$ as feridas são incicatrizáveis."

(Carolina Maria de Jesus)

A partir das vozes convergentes das epígrafes, pensou-se em fazer um estudo comparado de textos poucos estudados das escritoras Carolina de Jesus e Clarice Lispector, na hipótese de que essa articulação entre autoras socioculturalmente diferentes poderia revelar vozes silenciadas às quais mostram o posicionamento do indivíduo como sujeito social.

O sujeito parece viver condicionado aos discursos - veículo das representações ou autorrepresentações. Os discursos não são meios transparentes que mostram o mundo como ele é, mas perfazem e recriam rotas e roteiros para uma compreensão e participação nessa realidade. Por isso, em narrativas confessionais existe um paradoxo entre a realidade vivida e a transcrita: a narrativa confessional (escrita em primeira pessoa) é ficção quando a consideramos recriação do "eu”, pois é impossível passar para a página a realidade fielmente retratada (MACIEL, 2005). A crítica que está sendo tecida sobre os pressupostos da representação, nas narrativas de mulheres, é sobre a ideia de se pensar o referencial e a representação como estruturas estáticas nascidas no amparo do sujeito cartesiano, considerado o porta-voz dos logos e criador do discurso autorizado.

A linguagem em discursos, sendo um fator no posicionamento do sujeito, pode apontar para outras infinitas maneiras de representações de mulheres nos textos. E ao se falar ainda em textos escritos por mulheres, é bom lembrar que estes sujeitos podem relacionar-se como (auto)representação:

Un individuo (una mujer, en este caso) tiene múltiples posiciones de sujeto - identidades e identificaciones imaginarias que la interpelan, desde el marco de los discursos institucionalizados de autoridad: la Iglesia, el Estado, la ley. Lo importante es que las posiciones de sujeto son provisorias y relacionales, y surgen como respuestas a interpelaciones, a discursos que nos llamam. Todo ello supone que no tenemos solo una posición en el mundo, sino que nos podemos mover entre fronteras, rechazando, polemizando o aceptando las posiciones de sujeto que nos interpelan (ZAVALA, 1993).

Aqui se pode pensar que o posicionamento da mulher, ao assinalar um lugar relacional e dialógico nas identificações hegemônicas, inicia um trabalho de 
desconstrução ${ }^{2}$ das modalidades discursivas patriarcais, hegemônicas.

Nesta perspectiva, Meu estranho diário e Aprendendo a viver são objetos comparáveis dentro dos estudos literários pelo viés da "diferença". Esta análise parte de uma visão de que gênero, assim como raça, classe, etnia, nacionalidade, são categorias da diferença que se inscrevem no horizonte dos processos históricos, políticos, culturais e das práticas teórico-críticas da contemporaneidade.

Carolina é negra, semianalfabeta e pobre, Clarice é branca e de classe média alta. Sabendo que o signo "mulher" não é uma categoria unívoca, questionam-se quais seriam os discursos das mulheres (auto)representadas nos textos selecionados, haja vista que as autoras são de raça e classe social diferentes?

Carolina Maria de Jesus passou sua infância em Sacramento ${ }^{4}$, interior de Minas Gerais, migrando ainda jovem à cidade de São Paulo em busca de uma vida melhor, com apenas dois anos de escolaridade. Nesta grande cidade, Carolina trabalhou como empregada doméstica em diversas casas de família até que, grávida de seu primeiro filho, já não a aceitaram para esse tipo de serviço. Muda-se então para a favela do Canindé, onde teve mais dois filhos (um

2 Conceito alavancado por Jacques Derrida que não significa destruição, mas desmontagem, decomposição dos elementos da escrita ou decomposição de uma estrutura.

3 É de Jacques Derrida a teorização da différance (1968): uma espécie de "emblema da Desconstrução". O crítico trata do exercício da Desconstrução sobre as diferenças entre os pares binários existentes como configurações possíveis, por exemplo, da sexualidade.

4 A infância de Carolina Maria de Jesus em Sacramento é rememorada na obra póstuma Diário de Bitita (Obra publicada primeiramente na França (1982), e, anos depois, no Brasil (1986), sendo reeditada em 2007 pela Editora Bertolucci). menino e uma menina) e começa a escrever seus textos, também, a catar lixo para sobreviver. Ao publicar seu primeiro livro ${ }^{5}$, Quarto de despejo (cujos fragmentos foram publicados primeiramente em jornais), muda-se do barraco da favela para uma casa de alvenaria no Alto de Santana, zona norte de São Paulo. No fim de sua "carreira", muda-se para um sítio em Palheiros - SP, onde continua a escrever seus textos (muitos destes ainda inéditos) e morre em 1977.

Enquanto Clarice Lispector nasceu em Tchetchelnik na Ucrânia, nas palavras da autora, "uma cidade tão pequena que nem figura no mapa", em 10 de dezembro de 1920, num momento em que seus pais, judeus, se preparavam para imigrar para o Brasil, fugindo da perseguição antissemita e da Revolução Bolchevique de 1917. Clarice chegou a terras brasileiras com dois meses de idade, juntamente com a família, estabelecendo-se primeiramente em Maceió (AL) e mais tarde em Recife (PE). Em 1943, aos 23 anos, casou-se com o diplomata Maury Gurgel Valente, passando a residir em vários países, até retornar ao Brasil em 1959. Clarice Lispector foi formada em Direito, estudou latim, viveu em Nápoles, Washington, Berna, traduziu textos para o português, atuou como repórter e jornalista. Era dona de uma prosa densa, rebuscada, rica em inovações sintáticas e recursos linguísticos. Morre no Brasil, no mesmo ano em que Carolina de Jesus, 1977.

Apesar das diferenças étnico-sócioculturais das escritoras, a proposta aqui de ler Carolina ao lado de Clarice não está

5 Este primeiro livro foi publicado em 1960; Outros textos: Casa de Alvenaria (1961); Provérbios (1963); Pedaços da fome (1963); obra póstuma: Diário de Bitita (1986) e Meu estranho diário (1996). 
desprovida de relevância. Afinal, acredita-se enxergar uma cartografia de mulheres mais abrangente da margem à elite, a partir da análise dos textos: Meu estranho Diário ${ }^{6}$ (1996), de Carolina; e Aprendendo a Viver ${ }^{7}$ (2004), de Clarice.

É possível verificar até que ponto existe (ou não) a repetição de estereótipos criados por um mundo estruturado em binarismos. São essas formas possíveis de consciências enunciadas de acordo com o contexto situacional de gênero ${ }^{8}$ que se deseja mostrar por meio da análise dos textos selecionados.

\section{Aprendendo a viver com Meu estranho DIÁRIO: UM BARALHADO DE DIFERENÇAS}

Geralmente, em uma narrativa em primeira pessoa de autoria de mulher, a representação do mundo é produzida a partir de uma posição que exige sua definição

6 A obra Meu estranho diário (1996) é uma publicação póstuma, organizada pelos pesquisadores José Carlos S. B. Meihy e Robert M. Levine, são apresentadas três trajetórias de Carolina: no Quarto de despejo; na Casa de Alvenaria; e no Sítio onde morre em 1977.

7 Aprendendo a viver é uma seleção das crônicas confessionais escritas por Clarice Lispector na década 1970. Organizado por Pedro Karp Vasquez, o livro reúne uma série de textos em que a escritora conta sua própria vida, da infância até as reflexões sobre a morte. É narrado em primeira pessoa, detalhando passagens marcantes de sua história, divagando sobre os temas mais variados, revelando particularidades de seu cotidiano e esmiuçando seu processo criativo.

8 Gênero não como uma construção do masculino e feminino com base na diferença sexual em que se especificam comportamentos e atitudes aos sexos, mas sistema de significação que nos rodeia desde o nascimento. Teresa de Lauretis (1994), em Tecnologias de Gênero, desconstrói aquele conceito de gênero marcado pela diferença sexual, conceituando como uma representação e autorrepresentação, produto de várias tecnologias sociais (cinema, discurso, epistemologias, práticas institucionais e práticas da vida cotidiana, entre outras). na diferença (CATELLI, 1996). Corrobora Bahia, em sua Tese de Doutorado (2000, p. 70), dizendo que "escrever como mulher é lançar-se num horizonte para além do que o movimento histórico lhe vinha permitindo".

Contudo, segundo Cíntia Schwantes, em "Espelho de Vênus" (2009), a (auto)representação da mulher se dará de forma tensa, posto que as escritoras tenham uma representação ambígua, dependendo de sua raça e de sua classe social. Acredita-se que o signo "mulher" não é uma categoria unívoca - os fatores de classe e raça interferem na construção de uma significação de mulher, podendo indicar aporias no interior dos discursos das autoras que porventura buscam um diálogo com as representações hegemônicas de gênero.

$\mathrm{Na}$ literatura, o representado recebe toda uma carga de impressões do autor sobre o mundo. E quando se fala de uma literatura confessional de mulher, a carga de impressões parece aumentar, pois a mulher é sujeito e objeto da representação literária ao mesmo tempo: há o sujeito empírico, o eu discursivo e o protagonista, sendo que os três não se confundem. O tom de conversa informal próprio da narrativa confessional traz "experiências" pessoais, o que nos leva a apontar os textos Meu estranho diário e Aprendendo a viver como contundentes para um estudo da literatura fora dos discursos hegemônicos.

A favelada Carolina escreve com o desejo de publicar seus textos (e ser reconhecida como letrada ou poeta), rompendo com valores e comportamentos esperados de uma mulher nos anos 1950 a 70 do século XX. No dia 7 de julho de 1958, para se defender, narra: "Eu sou da favela do Canindé. Sei cortar de gilete e navalha e estou aprendendo a manejar a peixeira" (JESUS, p. 73). 
Carolina de Jesus foi uma mulher favelada, mãe solteira, chefe de família que demonstrou as dificuldades enfrentadas, em fins de 1950, para sustentar, sozinha, três filhos de pais diferentes.

A representação da mulher em textos de Carolina de Jesus parece, portanto, contrariar o "sistema falocêntrico", o sistema familiar pré-estabelecido como "normal", segundo o qual os homens deveriam ocupar o lugar de provedores financeiros e chefes de família e as mulheres encarregarem-se das atividades domésticas, como cuidar dos filhos, da casa, da comida, entre outros afazeres. A realidade da favelada contrastava com o padrão estabelecido como "normal". Assim Carolina é deslocada, deseja sempre ser lançada para fora da estrutura social vivida.

Seguindo as teorizações de Sílvia Nunes (2000, p.108-109), histérica, desvairada, enlouquecida, geniosa e perigosa são algumas representações da mulher que foram se inscrevendo no imaginário social desde o século XVIII. E que nos anos entre 1950 e 1970, no Brasil, ainda encontravam ressonância para a nomeação da mulher em épocas de ditadura. Principalmente da mulher que participou passivamente do processo de modernização da cidade de São Paulo, e que sofreu ativamente as consequências dessa modernização, como Carolina de Jesus. Mas quais seriam as representações da mulher em textos de Clarice Lispector, que participou ativamente por ter tido acesso ao direito equitário da construção de construtos simbólicos de um processo econômico-social e político da época?

A partir daqui, acredita-se que se teriam representações de mulheres de acordo com o olhar de classe ou raça, como teriam diferenças em olhares de gênero, pois, como mostra Bourdieu (1999, p. 82), a representação da mulher imaginada pelo masculino teve sempre como objetivo gerar um estado de insegurança e dependência simbólica que torne a mulher alguém digno de ser considerado frágil. Mas haveria diferenças nas representações da mulher, a partir de olhares de escritoras socioculturalmente diferentes?

Segundo Showalter (1994, p. 44), as diferenças entre mulheres escritoras (classe, raça, nacionalidade) são determinantes literários significativos, contudo, "a cultura das mulheres forma uma experiência coletiva dentro do todo cultural, uma experiência que liga as escritoras uma às outras no tempo e no espaço". Como no texto de Carolina, é possível perceber no livro de Clarice o impacto da divisão hierarquizada de gêneros por meio de relatos confessionais alternados com divagações filosóficas.

A Clarice de Aprendendo a viver é a dona-de-casa que enfrenta os problemas de toda e qualquer mulher de classe média/ alta, preocupando-se com o orçamento doméstico, com a educação dos filhos, e que, ao contrário de Carolina, não deseja ser reconhecida como escritora: "Literata também não sou porque não tornei o fato de escrever livros 'uma profissão', nem uma 'carreira' (LISPECTOR, p. 47). Matéria extraída do cotidiano da própria autora, como em um jogo de espelhos, as vozes discursivas parecem ansiar por romper os preconceitos, a própria passividade, por arriscar uma nova vida, escrita com as tintas de uma subjetividade latente. Clarice, mulher burguesa, parece ser solidária com mulheres que vivem marginalizadas, como as empregadas domésticas, as negras, as migrantes, as pobres: "E eu sentia o drama social com 
tanta intensidade que vivia de coração perplexo diante das grandes injustiças a que são submetidas as chamadas classes menos privilegiadas" (LISPECTOR, p. 46).

Apesar das diferenças de classe econômica, Clarice e Carolina se encontram na situação-limite de mulher em um contexto sócio-histórico brasileiro dos anos de 1950 a 1970, sobretudo nos anos de chumbo da ditadura. Ambas parecem representar por meio de seus discursos o "paradigma $\mathrm{da}$ função da mulher, de denunciadora da injustiça e da repressão máxima ao instinto de vida". Ambas, cada uma a seu modo, parecem denunciar as "forças da morte" ${ }^{10}$ lá onde as forças da vida deveriam ser preservadas. Ambas fazem uso da palavra verbal para resistirem à imposição de um emudecimento político e de gênero, ou seja, de falar em lugar de quem é desconsiderado e já não sabe mais falar. É pela palavra que elas se opõem ao "instinto de morte" física, simbólica ou afetivo-emocional: "Mas não tenho nenhum poder. Só o da palavra, às vezes" (LISPECTOR, p. 126); "Não tenho força física, mas minhas palavras são incicatrizáveis" (JESUS, p. 33).

Os fragmentos periódicos que compõem Meu estranho diário desvelam três trajetórias de Carolina Maria de Jesus. A primeira parte, intitulada "Diários no quarto de despejo" (p. 31), trata exatamente

9 Em Figuras do feminino (2000), Adélia Bezerra de Menezes trata da história de Angélica, mãe de Zuzu Angel que lutou desesperadamente para denunciar a morte de s(eu) filho, preso político, em 1971, e acabou ela própria morrendo em um acidente incompreensível.

10 Op.cit. p. 57.

11 Os termos "instintos de vida" e "instintos de morte" advêm da Psicanálise e são representativos das forças construtivas e destrutivas que habitam todo Ser Humano (MAGNABOSCO, 2002). do início em que Carolina Maria de Jesus resolve escrever, e mais, tornar-se escritora a fim de angariar dinheiro para comprar uma casa fora da favela. Nessa época de miséria na favela do Canindé, às margens do rio Tietê, na cidade de São Paulo, Carolina escreve sobre as "lambanças dos favelados". É quando conhece Audálio Dantas $^{12}$, o repórter que lança no mercado editorial seu primeiro livro intitulado Quarto de despejo: diário de uma favelada. Na segunda parte, "Diários na casa de alvenaria" (p. 117), Carolina já é "uma celebridade", seu diário Quarto de Despejo está sendo vendido e traduzido no mundo inteiro $^{13}$. Já não mora mais na favela, mora em uma casa de alvenaria, como desejava. Têm contatos com escritores, editores, pessoas da alta sociedade, mas está sempre criticando a todos, afirmando não se dar bem com a vizinhança burguesa/branca. Na última parte do livro - "Diários no sítio" (p. 200) - é relatada a mudança de Carolina da casa de alvenaria para um sítio em Parelheiros/SP, com a esperança de encontrar paz longe das letras, dos brancos e da cidade. No sítio, Carolina Maria de Jesus se lamenta da vida, bem como continua a refletir e a questionar sobre a existência humana.

12 Audálio Dantas nascido em Tanque d'Arca, Alagoas, 8 de julho de 1929, é um jornalista brasileiro, premiado pela ONU por sua série de reportagens sobre o Nordeste brasileiro. Também foi presidente do Sindicato dos Jornalistas do Estado de São Paulo. Primeiro presidente da Federação Nacional dos Jornalistas (FENAJ) e deputado federal. Atualmente, Dantas é vice-presidente da Associação Brasileira de Imprensa (ABI).

13 O livro foi traduzido para as seguintes línguas: holandês, alemão, francês, inglês, checo, italiano, japonês, castelhano, dinamarquês, húngaro, polonês, sueco e romeno. E existiria uma $14^{\mathrm{a}}$ tradução, para russo, não confirmada. 
Percebe-se que Carolina, mesmo ao passar a conviver numa casa de alvenaria em Santana (bairro nobre de São Paulo da época), acusa as classes dominantes detentoras do poder aquisitivo e da ciência, e tudo aquilo que de alguma maneira lhes representam. Seu discurso ataca o outro, neste caso o branco; conforme analisa Nietzsche (1999), isso é característico dos povos "oprimidos", os quais desenvolvem o que o filósofo chama de "memória do ressentimento", que seria um discurso do dominado contra o dominante.

A casa de alvenaria permitiu a Carolina escrever outro diário intitulado Casa de talvenaria - diário de uma ex-favelada. Neste relato, a autora irá narrar outras dificuldades de adaptação, principalmente por não conseguir se enquadrar em outras representações de classe e gênero, o que gerou outros preconceitos e discriminações sobre sua pessoa:

[...] Eu ainda não habituei com este povo da sala de visita - uma sala que estou procurando um lugar para sentar."; “[...] Agora que estou mesclada com o povo fico observando os tipos de pessoas, classificando os seus carateres. Há os tipos trapaceiros fantasiados de honestos. São os cínicos. Tem duas faces. Tipos que querem ser granfinos sem ter condições de vida definida. Sonham com o impossível, aludindo a cada instante: - Se eu tivesse dinheiro... Penso que eles devem dizer assim: - 'se eu tivesse coragem para trabalhar'. Estou ficando nervosa com os aborrecimentos diários. Tem dia que não escrevo por falta de tempo. [...] O que sei dizer é que a minha vida está muito desorganizada. Estou lutando para ageitar-me dentro da casa de alvenaria. E não consigo. Minhas impressões na casa de alvenaria variam. Tem dia que estou no céu, tem dia que estou no inferno, tem dia que penso ser a Gata Borralheira. (JESUS, p. 119)

Essas contradições e aporias começaram a ser uma constante na "experiência" de Carolina e terminaram por gerar uma instabilidade ainda maior quanto a seus pontos de apoio afetivo-emocional. Até a escrita, que sempre foi um ponto de apoio importante em sua vida, também, acabou sendo afetada por essas contradições que a colocavam num entre-lugar.

É paradoxal, tem consciência social, mas ao tratar com seus vizinhos favelados, aparta-se, sente-se diferente, superior, define-se como cidadã intelectual: "Nunca feri ninguém. Tenho muito senso! Não quero ter processos. O meu registro Geral é 845.936" (JESUS, p.36); ironicamente, tem que trabalhar catando papel no lixo - o mesmo papel que usa para escrever; é negra, exalta a beleza negra, mas, simultaneamente, não quer ter relações amorosas com negros, considera-os vítima de um contexto histórico cruel e atribui a cor preta às várias mazelas sociais. Carolina condena a violência e se intromete nas brigas comportando-se, às vezes, com violência e ameaças: "Eu chinguei o Chico de ordinario, cachorro, eu queria ser um raio para cortar-lhe em mil pedaços" (JESUS, p.44). Passa a morar numa casa de alvenaria, mas continua a sentir-se deslocada, até que morre isolada em um sítio.

A visão de mundo de Carolina de Jesus, em Santana, ganhava outros referenciais 
que não mais simplesmente os da favela. Agora, mais que antes, maldizia a cidade dos brancos e projetava no campo o ideal de pureza e de vida. Contudo, na lista dos aspectos que perduram, para Carolina, fica claro que os velhos estereótipos do tipo "os políticos são os culpados", "os livros são bons educadores", "os homens são volúveis", "é triste a vida de uma mulher sem homem", "mulheres são fofoqueiras", resistem e mantêm-se como referenciais de sua visão de mundo.

Isso acontece porque, segundo Madalena Magnabosco (2002), as forças político-econômicas e sociais que regem na sociedade dividem Carolina de Jesus em incluídos e excluídos, implicando uma diferença estabelecida e estandardizada entre homens/mulheres, ricos/pobres, cultos/incultos, negros/brancos. A estrutura binária assim montada, ao ser Carolina de Jesus inserida na categoria de mulher/semi-analfabeta/negra, de acordo com Madalena Magnabosco (2002, p. 62),

[...] foi pega por uma perda de distância que impossibilita um olhar crítico e reflexivo, ao confundir sujeito e contexto, referência e referente, múltiplos eus com identidade unívoca pelo espaço ocupado. Imersa e sem distância, ela se perde não na dicotomia cidade/favela, mas na evidência da impossibilidade de reconhecer-se por todo seu percurso e história.

O discurso caroliniano, portanto, é tenso e ambíguo. E a própria representação desse "eu mulher" se faz com ambiguidades.
Sobre as mulheres da favela, é recorrente a referência a elas como fofoqueiras, escandalosas, bagunceiras, desordeiras etc. Características aparentemente incompatíveis com uma mulher culta, uma intelectual, uma escritora, segundo a narradora caroliniana:

Tenho pavor destas mulheres da favela. Tudo quer saber! A lingua delas é como os pés de galinha. Tudo espalha. Está circulando o rumor que eu estou gravida! E eu, não sabia! Nas favelas as bagunceiras são as mulheres. As intrigas delas é igual a de Carlos Lacerda que irrita os nervos. (JESUS, p. 38).

Aos poucos, a narrativa mostra uma integração de Carolina ao grupo de mulheres da favela indesejada, porém inevitável. A protagonista participa da "vida social" da favela, como parte do grupo, e na tão famosa torneira (lugar onde as fofocas aparecem), rende-se: "O soldado Flausino disse-me que a C. era amante do pai. Que ela havia dito que ia com o pai e ganhava 50 cruzeiros. Eu contei na torneira e as mulheres disseram que havia desconfiado." (JESUS, p. 102).

Percebemos que a narrativa de Carolina Maria de Jesus revela a ambiguidade do "eu caroliniano" que se apresenta como tessitura e, assim, proclama uma rede discursiva que apresenta diversas "Carolinas" dentro de uma estrutura binária: a educada e a mal educada, por exemplo. O "eu caroliniano" interpelado pelo outro (mulher culta - para citar um exemplo) interpreta o mundo de diversas formas conforme lhe convêm: assume posições ambíguas e até contraditórias no discurso.

Ao contrário de Clarice Lispector, que parece ter claro seu projeto, assumindo de forma clara sua posição: "Eram oito conferências seguidas de debates. Aviso às 
feministas: eu era a única mulher do grupo" (LISPECTOR, p.123). Clarice, mesmo interpelada pela pobreza, segue firme sua posição de denunciadora e questionadora de tudo, sem se deslocar enquanto sujeito: "Ah que me perdoem os que não têm o que comer; o que vale é que esses não são os que me leem" (LISPECTOR, p. 102).

Assim, em Aprendendo a Viver, Clarice tem um olhar crítico e reflexivo, o que possibilita reconhecer-se por todo seu percurso e história, perseguindo dúvidas e inquietações relativas ao sujeito: "Até hoje só consegui nomear com a própria pergunta" (p. 75), inclusive uma de suas crônicas é intitulada "Sou uma pergunta". Seu discurso perturba o leitor por desconstruir binarismos ou simplesmente mostrar que o mundo é construído sob estes: branco versus preto, bonito versus feio - "eu queria ser feia, isso representava meu direito total à liberdade" (LISPECTOR, p. 57); talvez por isto Clarice alerta que sua "lucidez" pode se tornar um "inferno humano": "o que me irrita é que tudo tem de ser do modo certo, imposição muito limitadora" (LISPECTOR, p. 73 - grifo da autora); "Só posso escrever se estiver livre, e livre de censura, senão sucumbo" (LISPECTOR, p. 50).

O discurso clariceano, embora simples, baseado em fatos corriqueiros e banais, quase sempre centralizado em mulheres (ela mesma, amigas, empregadas) apresenta um mundo novo e perturbador, desestabilizador da ordem aparente. Clarice questiona tudo, por perceber como a sociedade e até mesmo o pensamento está estruturado: "Depois que descobri em mim mesma como é que se pensa, fazendo comigo mesma negociatas, nunca mais pude acreditar no pensamento dos outros" (LISPECTOR, p. 74).
Ao contrário de Carolina, Clarice tem consciência de seu projeto feminista, sabe que o pensamento da sociedade está estruturado num sistema binário, cheio de preconceitos. Consciente disso, Clarice joga discursivamente, dialoga até mesmo com o desconhecido:

- Posso dizer tudo?

- Pode.

- Você compreenderia?

- Conpreenderia. Eu sei de muito pouco. Mas tenho a meu favor tudo o que não sei e - por ser um campo virgem está livre de preconceitos. Tudo o que não sei é a minha parte maior e melhor: é a minha largueza. É com ela que eu compreenderia tudo. Tudo o que não sei é que constitui a minha verdade. (LISPECTOR, p. 74)

Clarice Lispector questiona os saberes instalados no mundo fazendo com que os limites de Verdade e Mentira caem por terra... O fato é que ela dialoga com o mundo com desconfiança: "o que é mesmo que eu estava tentando pensar? Talvez isso: se a mentira fosse apenas a negação da verdade, então este seria um dos modos, por negação, de provar a verdade" (LISPECTOR, p. 73). Ainda nas crônicas "Supondo o errado" e "Supondo o certo", Clarice mostra como não são nítidas essas fronteiras: "Suponhamos que eu seja uma criatura forte, o que não é verdade" e "Suponhamos que o telefone ande em toda a cidade enguiçado, o que é verdade" (LISPECTOR, p. 42). Neste "brincar de pensar", a narradora clariceana questiona o que é verdade, mostrando ao 
leitor que ele pode escolher dizer "sim" ou "não" para o mundo.

A narradora clariceana escolheu dizer ao mundo que, como mulher, tornou-se forte: "Um domingo de tarde sozinha em casa dobrei-me em dois para a frente - como em dores de parto - e vi que a menina em mim estava morrendo. Nunca esquecerei esse domingo. Para cicatrizar levou dias. E eis-me aqui. Dura, silenciosa e heróica. Sem menina dentro de mim" (LISPECTOR, p. 82). Esse eu clariceano passa de menina criada sem mãe para aquela que não precisa pertencer a ninguém: é um ser livre. A liberdade é uma constância neste texto: "uma sede de liberdade me acordaria" para viver. Aprende-se a viver, de acordo com a autora-narradora, com a luta pela liberdade. Assim diz na crônica intitulada "Seguir a força maior": "É determinismo, sim. Mas seguindo o próprio determinismo é que se é livre. Prisão seria seguir um destino que não fosse o próprio. Há uma grande liberdade em se ter um destino. Este é o nosso livre-arbítrio" (LISPECTOR, p. 94).

Em Clarice Lispector, de simples acontecimentos, nasce uma prosa poética densa, que questiona e transgride o mundo patriarcal. Em meio às lembranças, os bichos, Clarice, como ela mesma diz, "pretende pôr em palavras um mundo inteligível e um mundo impalpável" (LISPECTOR, p. 47). Este mundo inteligível é um mundo em que homens compreendem que precisam se ajoelhar diante das mulheres; onde a protagonista Clarice recebe elogios de outro homem ao lado de seu marido: "É com mulheres como esta que contamos para reconstruir a Itália" (LISPECTOR, p. 52); e onde a autora-narradora vê sua cozinheira dominando o futuro: "Dói-me até o corpo ao pensar que não saberei jamais como o mundo será daqui a milhares de anos. Por outro lado, continuei, nós estamos engatinhando até depressa. $E$ a toada que a moça cantava vai dominar esse mundo novo: vai-se criar sem saber" (LISPECTOR, p. 70).

Diante do "mundo velho" e enxergando o "mundo novo", Clarice estabelece um debate crítico com seu tempo. O seu texto promove a emergência e a inscrição de um discurso feminista na história, por meio do posicionamento crítico da narradora-escritora acerca da diferença de classe e gênero, assumindo sua posição discursiva diante dos fatos narrados.

Clarice e Carolina descrevem seu cotidiano de forma descontínua, sob forma de escrita diária ou jornalística semanal, registrando acontecimentos que parecem ser um fazer, desfazer, fazer um resumo de existir, de ser interpelado pelo outro. Por esta razão, Rita Schmidt (1999, p. 29) argumenta que, num âmbito geral, pode-se dizer que o principal aporte feminista à produção de conhecimento ocorre na construção de novos significados, na interpretação das experiências das mulheres no mundo, de modo que a realidade, como construção imaginária e simbólica, possa ser interrogada, repensada e transformada.

Fazendo esse rápido passeio de Aprendendo a Viver a Meu estranho diário, podemos dizer que existe no Brasil uma literatura que alcançou superação em relação aos binarismos, cujas personagens tentaram se libertar das amarras que as atavam ao modo de pensar e agir: Carolina tentou, Clarice conquistou. 
3. JogAndo AS CARTAS NA MESA: DISCURSOS EM DIÁLOGO

Por meio do diálogo entre Aprendendo a viver e Meu estranho diário foi possível verificar as diferenças de posições discursivas em Carolina de Jesus e Clarice Lispector não como paradigma - mas como tensões necessárias à quebra do habitual monólogo do discurso cultural hegemônico sobre a mulher.

A diferença na perspectiva do olhar tem feito que a memória afetivo-emocional do sujeito confessional traga um questionamento sobre os conceitos de representação. Ao narrar a partir de uma voz não gendrada pelos discursos dominantes, como o de Clarice Lispector, o sujeito mulher presenta-se e, diante dessa outra posição enunciativa, questiona o discurso hegemônico. A narradora-autora Clarice Lispector apresenta-se como produtora consciente de discursos e saberes e não como consumidora do que "se diz para" e "sobre ela". A narradora-autora Carolina de Jesus, entretanto, encontra-se num entre-lugar: nem totalmente consumidora, nem totalmente produtora consciente dos discursos.

Apontamos que as obras das referidas autoras tentam se desviar de um sistema hegemônico, oficial, buscando um espaço de autorrealização, o direito da palavra, a apropriação do discurso, a insubordinação, o alvedrio de falar, de se expressar, fazendo-se ouvir, não importa se de sua marginalidade ou de sua multiplicidade discursiva, o que parece importar mesmo é marcar um lugar (ou um entre-lugar).

É possível afirmar que as narrativas selecionadas possuem uma característica fundamental de solicitar espaço para o reconhecimento público e pessoal de vozes antes marginalizadas do reprimido social e político. Respondendo às interpelações de opressões culturais em relação à mulher, os textos de Carolina e Clarice revelam o poder da palavra, como afirmam nas epígrafes iniciais deste trabalho. No mundo público, a palavra confessional vem denunciando a repressão dos pobres, a invisibilidade da mulher e tem requisitado uma transformação sobre essas práticas culturais. As narrativas analisadas vêm ao encontro dessas questões, podendo levar os leitores a pensar sobre as práticas culturais de ontem e de hoje, sobre, principalmente, o gênero no Brasil.

\section{REFERÊNCIAS}

BAHIA, M. F. O legado de uma linhagem (A literatura memorialística feminina). Tese de Doutorado em Literatura Comparada. Faculdade de Letras da UERJ. Rio de Janeiro. Junho de 2000.

BOURDIEU, P. A dominação masculina. Tradução de Maria Helena Kühner. Rio de Janeiro: Bertrand Brasil, 1999.

CATELLI, N. El diario íntimo: una posición femenina. Revista de Occidente: el diario íntimo. Fragmentos de diarios españoles (1995 - 1996). Madrid: Fundación José Ortega e Gasset, n. 182 - 183, jul./ago./1996.

DERRIDA. J. A escritura e a diferença. São Paulo: Perspectiva, 1971.

JESUS, C. M. de. Meu estranho diário. Meihy e Levine (Orgs.). São Paulo: Xamã, 1996.

LAURETIS. T. de. "Tecnologias de gênero". In: HOLANDA, H. B. de. (Org.). Tendências de impasses: o feminismo como crítica da cultura. Rio de Janeiro: Rocco, 1994.

LISPECTOR, C. Aprendendo a viver. Rio de Janeiro: Editora Rocco. 2004. 
MACIEL, S. D. et al. Termos de literatura confessional em discussão. Disponível em: <http://www.ceul.ufms.br/guavira/numero1/ maciel_sheila_e.pdf>.Acesso em: 05 out. 2005. MAGNABOSCO, M. M. Reconstruindo imaginários femininos através dos testemunhos de Carolina Maria de Jesus. Tese de Doutorado. FALE, Programa de PósGraduação em Letras: Estudos Literários, UFMG - Belo Horizonte, 2002.

MENEZES, A. B. Figuras do feminino. São Paulo: Ateliê Editorial, 2000.

NUNES, S. A. O corpo do diabo entre a cruz e a caldeirinha: um estudo sobre a mulher, o masoquismo e a feminilidade. Rio de Janeiro: Civilização Brasil, 2000.

SCHWANTES, C. Espelho de Vênus: questões da representação do feminino. Disponível em: http://www.amulhernaliteratura.ufsc.br/ artigo_cintia.htm. Acesso em 01/03/2009.

SHOWALTER, E. A crítica feminista no Território Selvagem. In: HOLLANDA, Heloísa Buarque de. (Org.). Tendências e impasses o feminismo como crítica da cultura. Rio de Janeiro: Rocco, 1994.

SCHMIDT, R. T. Recortes de uma história: a construção de um fazer/saber. In: RAMALHO, C. Literatura e feminismo: propostas teóricas e reflexões críticas. Rio de Janeiro: Elo Editora, 1999. ZAVALA, I. Las formas y funciones de una teoría crítica feminista. Feminismo dialógico. In: ZAVALA, I. Breve historia feminista de la literatura española. Barcelona: Anthropos, 1993.

Recebido para publicação em 26 ago. 2013. Aceito para publicação em 12 jan. 2014. 